\title{
Measuring E-Readiness of Students of Public Universities in Kenya for Digital Learning during the COVID 19 Pandemic and Beyond - A Survey of the Cooperative University of Kenya
}

\author{
Duncan Nyale \\ School of Computing and Mathematics \\ The Cooperative University of Kenya \\ Nairobi, Kenya
}

\begin{abstract}
The main purpose of this paper is to assess the e-capacity of the students of The Cooperative University of Kenya to access and use digital platforms of learning at present and beyond. The need for this urgent study is occasioned by the impact of COVID 19 which has stopped on campus learning at all institutions in Kenya; thus necessitating an urgent shift towards digital learning for all students to mitigate against delays that will otherwise have adversely affected their graduation schedules. Three main variables derived from the Harvard Center for International Development (CID) and Asia-Pacific Economic Cooperation (APEC) models - Human skills, Infrastructure and Connectivity - were used to craft the evaluation criteria. The results show that $(74.87 \%)$ of the respondents can access LMS via smart phones not computers which insinuates that Mobile Learning (m-Learning) is the most effective digital learning model that can be adopted by the University in the short term to quickly mitigate against the effects of the lack of face to face learning occasioned by social distancing guidelines due to COVID 19.
\end{abstract}

Keywords: ICT: - Information and Communications Technology, LMS: - Learning Management System, CUK: - Cooperative University of Kenya, COVID 19: - Corona Virus Disease 2019

\section{INTRODUCTION}

The disruption of the world order by the COVID 19 pandemic has not spared institutions of higher learning. An abrupt interruption of face to face learning has created a very urgent need to incorporate all on campus students to e-learning platforms. This was unprecedented and therefore no plans were in place to do this. It is therefore important to gauge the capacity of the main stakeholders of the institutions (students) to adopt this mode of training effective immediately. This paper aimed to do just that by running a quick survey to ascertain the e-readiness of the Cooperative University of Kenya students currently in session during the pandemic to quickly adopt and shift to the e-learning mode of education as soon as possible to minimize the disruption to their learning during the pandemic period and beyond.

The university already has a running LMS which mainly services students in the Institute of Open, Distance and eLearning (I-oDEL). The system is also used to run select common courses for on Campus students. However, it must be noted that a full scale migration to full e-learning mode has never been envisaged before making this abrupt need even more challenging.

E-Readiness can be defined as the degree to which a community is prepared to participate in the digital age (Networked World). A high level of e-readiness also contributes positively towards the realizations of an institutional goal (Kashorda \& Waema, 2014). E-Readiness assessment is meant to guide evolution efforts by providing benchmarks for comparison and gauging progress (Zaied, Khairalla \& Al-Rashed, 2007).

The results of this survey should go a long way towards informing the university of not only the current e-readiness of its students but also help in the decision, planning and rolling out of a full scope e-learning mode of training in the short, mid and long term.
This is more so due to the rapid rate of internet penetration throughout the world and Kenya in particular, coupled with dramatic advances in uses of information technology in business, industry, government and even education which makes it inevitable that there is likely to be a paradigm shift in the way university teaching, learning and assessment is done and very soon too considering the acceleration that has and still is being occasion by the COVID 19 pandemic.

\section{OBJECTIVES}

The goals of the study were:

a) To assess the e-preparedness of CUK students for digital learning

b) To analyze and gauge digital infrastructure and connectivity capacity of CUK students

c) To identify the key issues that need to be addressed in order to achieve the highest level of e-readiness

d) To create a base for the university to plan and roll out eLearning to all its students not only in the short term (pandemic period) but also in the long term.

\section{METHODOLOGY}

The population of the research comprised of the entire active under graduate students duly registered and active on the university portal.

The research instrument used for gathering information from the respondents was a questionnaire. The Google form method was used where the questionnaire was uploaded on the website then the respondents were invited to fill in the form through their email addresses and through official WhatsApp class groups. 


\section{DATA ANALYSIS AND PRESENTATION}

Some 1058 respondents filled the online questionnaire. Therefore, the findings presented in this section were based on the responded instruments; the analysis is as follows:

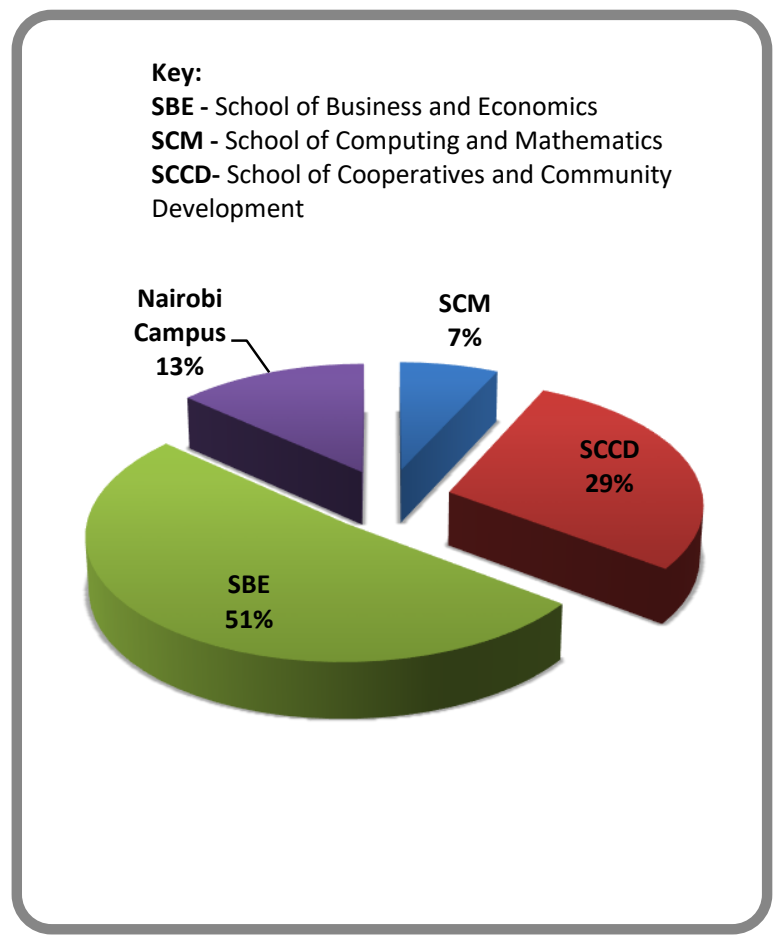

Figure 1. Analysis by School

Key:

DCIT - Department of Computer Science \& Information Technology

DCAM - Department of Co-operatives and Agribusiness Management

DCEM - Department of Community Development

and Environmental Management

DAF - Department of Accounting and Finance

DEE - Departm

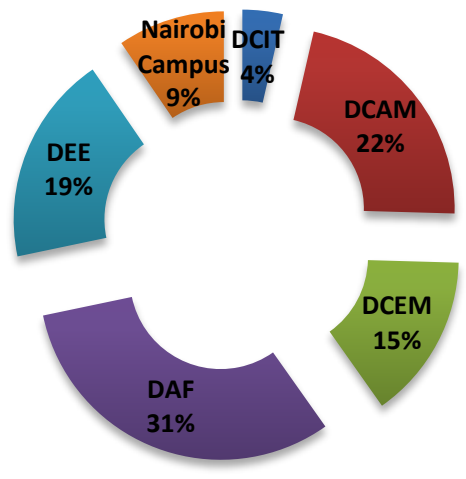

Figure 2. Analysis by Department

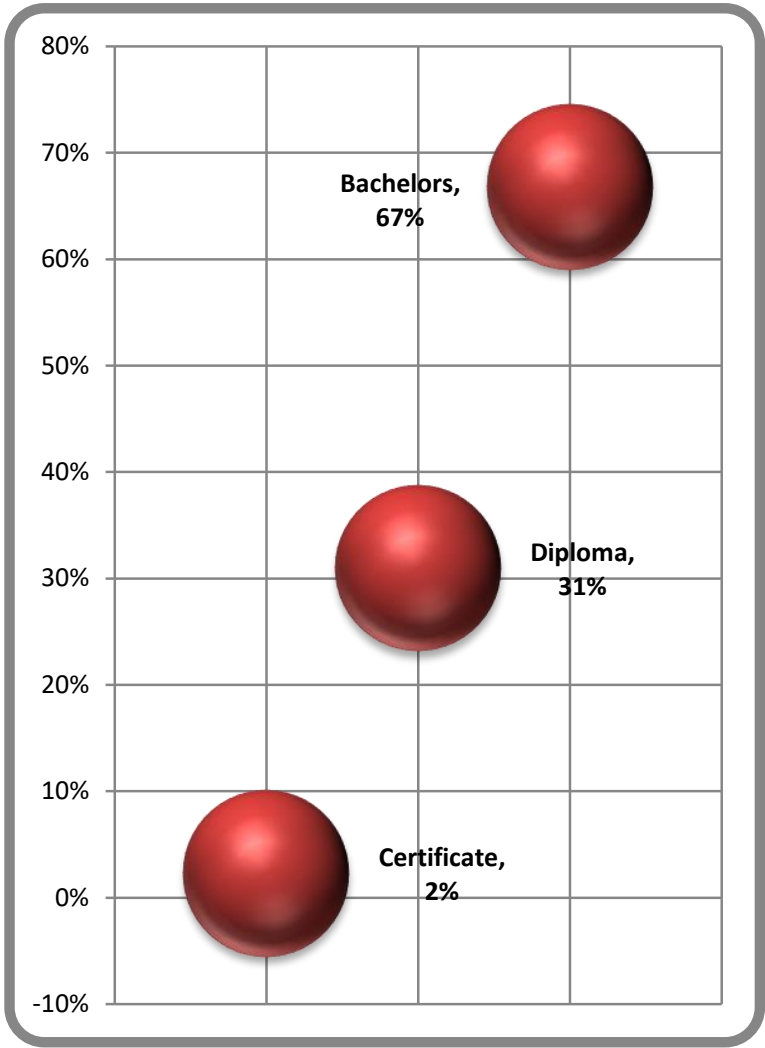

Figure 3. Analysis by Level of Study

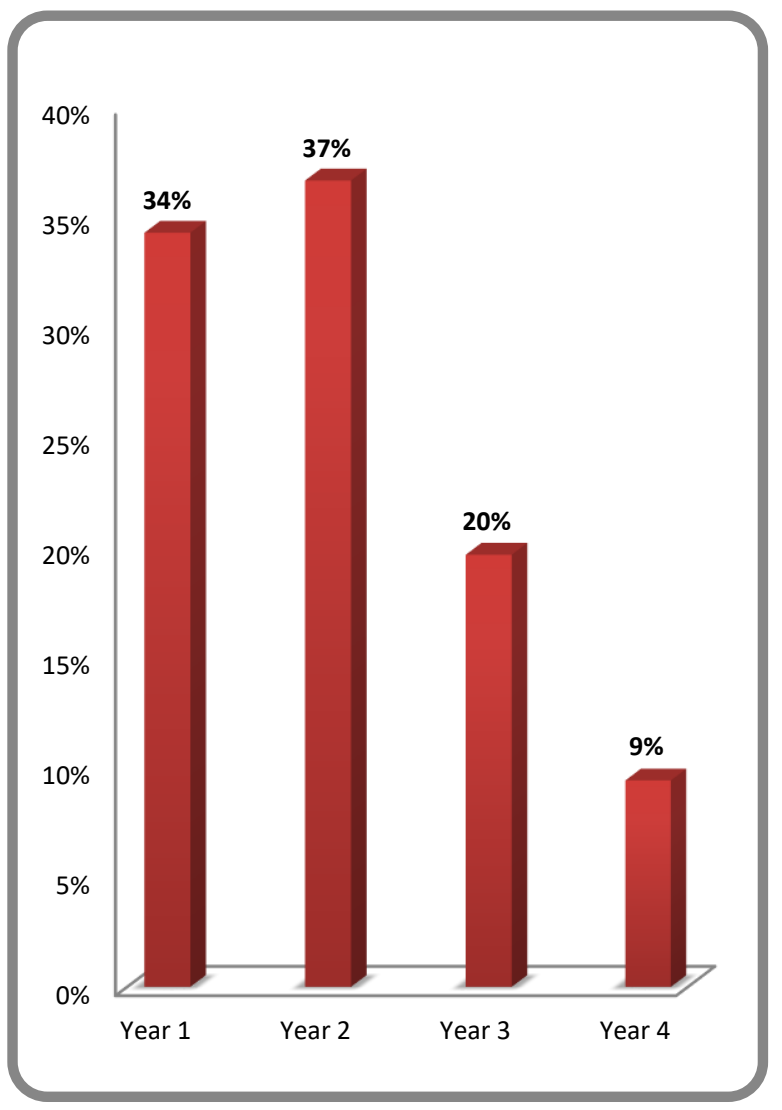

Figure 4. Analysis by Year of Study 


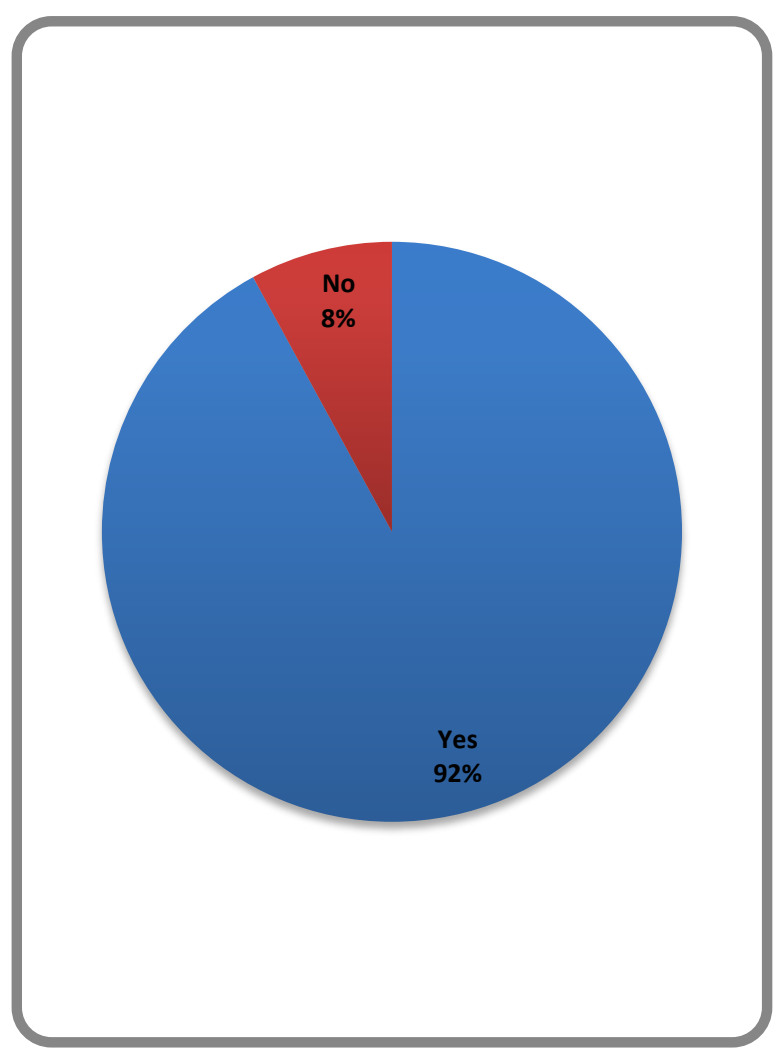

Figure 5. Percentage (\%) of respondents who have prior interaction with digital learning platforms

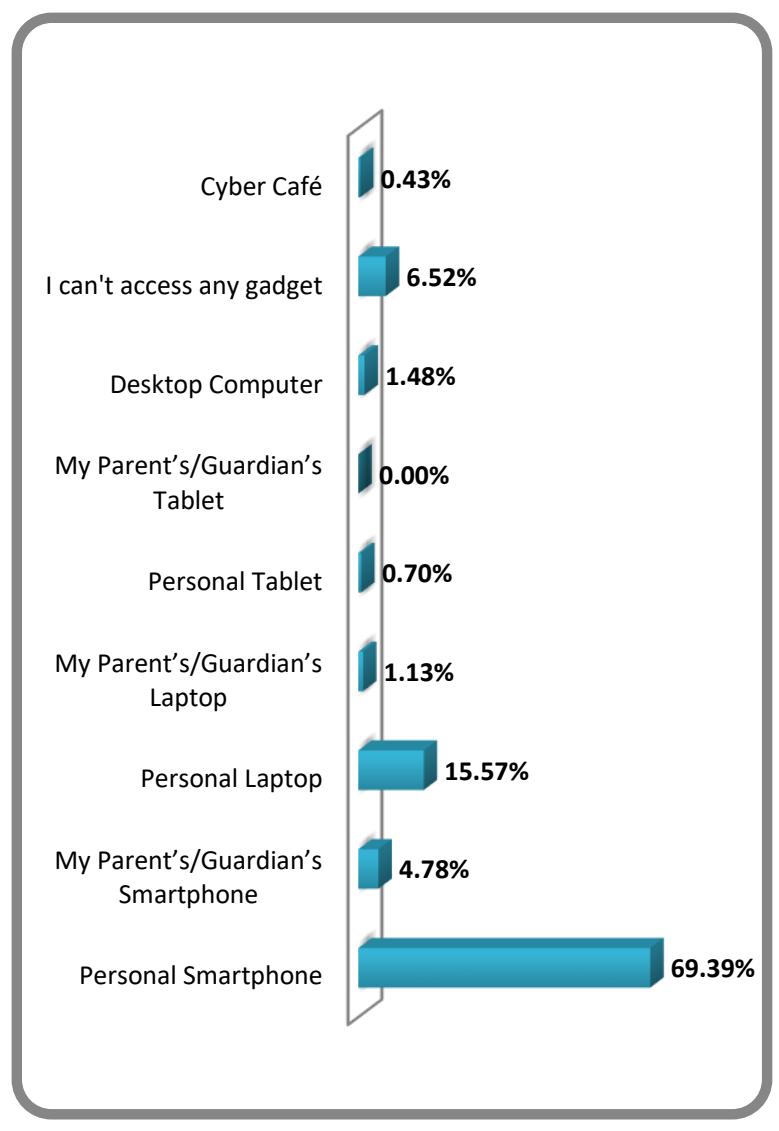

Figure 6. Analysis by Digital Gadget Access

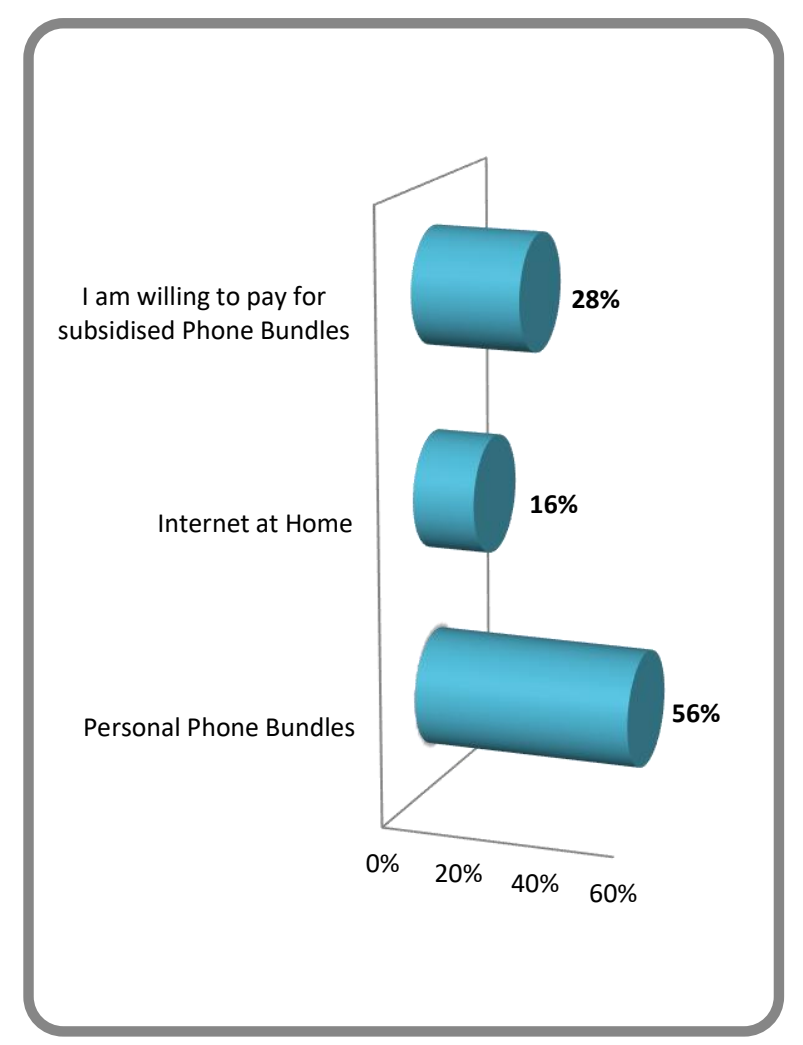

Figure 7. Analysis by Internet Connectivity Capacity

\section{SUMMARY OF FINDINGS}

- Majority of students have access to Smartphones and/or tablets $(74.87 \%$ ) compared to $18.79 \%$ who can access Desktops and Laptops

- A significant $6.52 \%$ of the respondents do not have access to any digital gadget usable for digital learning

- $85.66 \%$ of the students reported to have personal dedicated digital devices; which means a significant number of the remaining depend on communal, shared or borrowed resources.

- $92 \%$ of respondents reported to having prior interaction with digital learning platforms

- Only $16 \%$ of respondents have internet connectivity at home meaning most students will rely on smartphone internet.

- The majority of respondents were Bachelor's degree students $(67 \%)$.

\section{CONCLUSION}

The conclusion of this research reveals that although most students have had prior interaction with digital online platforms, more is needed to ensure its application will be a success. As is, not all students are fully e-ready to adopt this mode of learning, although this is more so due to infrastructural deficiencies rather than a lack of technical capacity considering their previous experience with digital delivery of academic content. More investment is therefore required to boost capacity in infrastructure, training and support to needy 
students otherwise some students will be left out and thereby require intervention measures later on to ensure their academic cycle is completed which will beat the core purpose of this anticipated migration to full digital learning during this pandemic and beyond. That being said, the findings reveal that immediate migration to digital learning is a feasible option for the University.

\section{RECOMMENDATIONS}

- Mobile Learning (m-Learning) is the most feasible option for the University to adopt in the short term considering the findings above.

- Infrastructural support is needed to ensure all students will be able to access this mode of study. More so for those without access to any digital gadgets.

- Regular capacity building as regards digital learning should be adopted for all university stakeholders

\section{REFERENCES}

[1] Kashorda, M., \& Waema, T. (2014). E-Readiness survey of Kenyan Universities (2013) report. Nairobi: Kenya Education Network

[2] Readiness for the Networked World (2001-2002; and 2002-2003) Online. (http://www.weforum.org/gitr) available at www.readinessguide.org

[3] Zaied, A. N. H., Khairalla, F. A., \& Al-Rashed, W. (2007). Assessing e-Readiness in the Arab Countries: Perceptions towards ICT Environment in Public Organizations in the State of Kuwait. Electronic Journal of E-government, $5(1)$. 